\title{
Private health insurance customer satisfaction. A consumer behavior exploratory study based on structural equation modeling
}

\author{
Adina ROTILEANU \\ Bucharest University of Economic Studies, Bucharest, Romania \\ arotilea@nyit.edu \\ Lucian-Florin ONIŞOR \\ Bucharest University of Economic Studies, Bucharest, Romania \\ luciano@ase.ro
}

\begin{abstract}
In the glocalization context, private health insurance local and international companies invested in Romania for over two decades, nevertheless the private health insurance adoption rate in the country was the lowest in the region. The purpose of this research is to analyze and understand the phenomena behind private health insurance customer satisfaction, designing a cognitive model and identifying the functional relationships between elements. The literature review provides various models that are related to customer satisfaction, from buying decision process to the relationships between perceived values, service consequence and expected service values that determines customer satisfaction. The developed conceptual model in six dimensions, including the output variable block for customer satisfaction, was the base for developing the research questionnaire. Developed on a structural equation modeling approach, the quantitative research results depict how customer satisfaction is mediating private health insurance and consumer behavior. Consequently, a private health insurance provider needs to adapt its products to increase people's motivation to purchase such a product and, after the acquisition, to improve the covered services to increase the beneficiaries' level of satisfaction. The generic contribution this paper brings is to present the private health insurance industry valences for Romania in the years 2017-2019 and the relationship between the product attributes, Customer Behavior and Consumer Satisfaction.
\end{abstract}

Keywords: customer satisfaction, private health insurance, cognitive modeling, consumer behavior, Romania.

\section{Introduction}

The new discoveries and the technology used in sanitary system are accompanied by significant investments. Hospitals and recovery units are constantly purchasing new equipment and new investigation tools (Zilberberg et al., 2020), this endowment being largely provided by public or private health insurance budgets (Cheng et al., 2009) (Heim et al., 2021). According to various medical insurance schemes studies across the world, private health insurance (PHI) systems are increasingly taken into account, from considering basic state offer packages and private supplementary health insurances (Boone, 2018) to the fraction covered by employer sponsored health insurance (Capatina, 2020). In countries that have already complex public-private health care systems, the reimbursement systems becomes a challenge for covering outpatient services (Dang et al., 2020) while in others, with growing elder population, the health insurance other social insurance policies financing may have negative effects in the saving rates and consequently, economic growth (Lim, 2020).

In Romania, a medium-sized Eastern European Country classified as an emerging market economy country, $41.7 \%$ of the workforce is employed in public institutions, steered by state (INSSE, 2019a). The gross monthly average salary per economy in 2019 was $1,022 €$ or the 
equivalent of 4,853 Lei (BNR, 2019). On one hand, given the average to low incomes of the population in general, a small percentage of people opt for and purchase a private health insurance themselves, 5\% according to the 'All about Health Insurance' national information campaign online survey (Ștefan, 2020), carried out in 2020. Within the same survey, 24\% of the respondents declared they have a health insurance policy from their employer. On the other hand, the need for certain medical services at lower costs or paid over longer period in smaller instalments causes a particular category of people to purchase a private health insurance. Therefore, 'over one third $(36 \%)$ of the survey participants would not be willing to allocate a monthly amount for private health services', according to the mentioned survey. This applies not only to countries where the population average income is medium to low but even in countries where the population receives medium to high incomes, such as Sweden where private health insurance 'has always played a highly marginal role' (Kullberg et al., 2019).

The private health insurance penetration in Romania is very low compared to other European countries, especially Ireland and Denmark where $47 \%$ respectively $44 \%$ of the population holds a private health insurance (Kullberg et al., 2019). In these countries, all employees must pay either a supplementary or complementary private health insurance on top of the principle of solidarity insurance, income based. The main question this research is addressing is what drives the private health insurance buying behavior and consumer satisfaction and how its satisfaction influences re-purchase decision.

At the time of insurance policy renewal, that is periodically, usually once every 12 month, the insured individuals may choose to either maintain or change the covered services package and/or the insurance provider (Puri \& Sun, 2021). These choices depend not only on the medical services included in a private health insurance but also on the extent to which these services were really used by the insured person in the covered period. Therefore, the level of satisfaction determines the consumer behavior in general and the consumer behavior of health services in particular (He et al., 2021), each person acting according to its level of satisfaction and making eventually some changes to the insurance policy covered package.

Studies have been carried out in multiple countries related to health insurance services satisfaction assessment (Trinh et al., 2020) in different stages of development of the respective countries taking into account the share of premiums per capita across products and where the cultural characteristics were found to have significant effects. This paper study is based on a structural equation model (Malhotra et al., 2017) whose analysis highlights the functional relationships between the private health insurance, the individuals' level of satisfaction and the consumer behavior. There are 3 hypothesis the authors considered (Figure 1):

H1: The Private Health Insurance characteristics directly influence the consumer behavior in the buying process and, based on the previous experience, subsequent repurchases;

H2: The purchase of a Private health Insurance directly influences the consumer's level of satisfaction;

H3: Customer Satisfaction mediates the Private Health Insurance purchase through consumer behavior. 


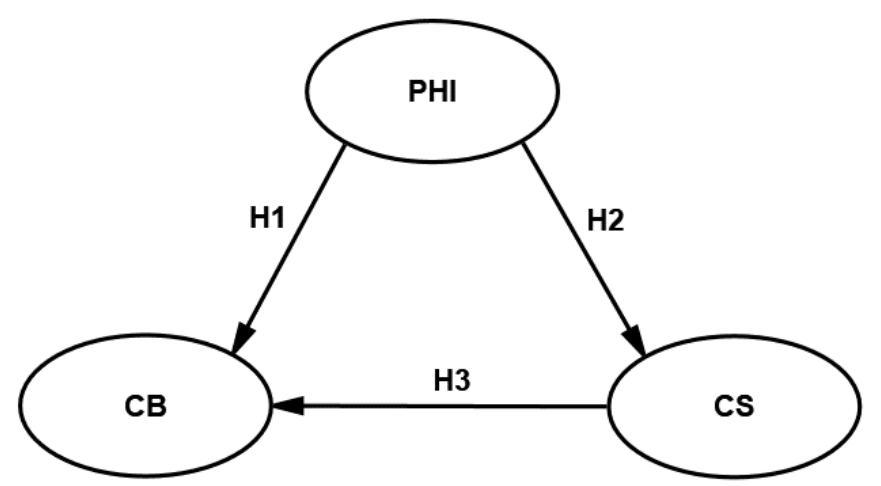

Figure 1. Schematic drawings of considered hypotheses

Note: $\mathrm{PHI}=$ Private health insurance, $\mathrm{CB}=$ Consumer behavior, $\mathrm{CS}=$ Customer satisfaction.

Source: Authors' own research.

The projected cognitive model considers 32 primary variables (Figure 2). However, for SEM functional model exploring purposes, this number was reduced to 9 variables, by merging indicators and using parceling (Matsunaga, 2008) methodology. The scientific importance of this paper is to present the Private Health Insurance industry framework for Romania and the factors influencing consumers buying decisions, encouraging the further industry development and insurance providers service structure.

\section{Literature review}

As described in the Howard-Sheth model (Sheth \& Howard, 1969). The theory of buyer behavior. New York: Wiley, the buying behavior leads to attention, as consumer response to the perceived volume of information, and to satisfaction. Satisfaction is ultimately responsible for future customer behavior and buying decisions, is a learning variable that builds trust in certain brands, products, and services, and it reflects the congruence between the purchase of a good or service and its usage (Cătoiu \& Teodorescu, 2004). To respond the question this paper is undertaking, the cognitive model depicted in Figure 2 has been created, and the confirmatory factor analysis will be tested against the quantitative research collected data to empirically validate it, with an a priori measurement specifications, by analyzing the indicators related to every factor and backwards the indicators variation caused by factors.

\section{The proposed model description in relation to market}

Subsequent models and theories analysis, the proposed cognitive model framework for customer satisfaction (Figure 2) displays all variables for creating a complex system. To be complete and integrated, the model elements synergistic effect should allow correlations between variables yet, for this research purpose, a reduced form scheme (Nicosia, 1966) may be used for co-variances analysis based on secondary functional relationships, as research will suggest. 


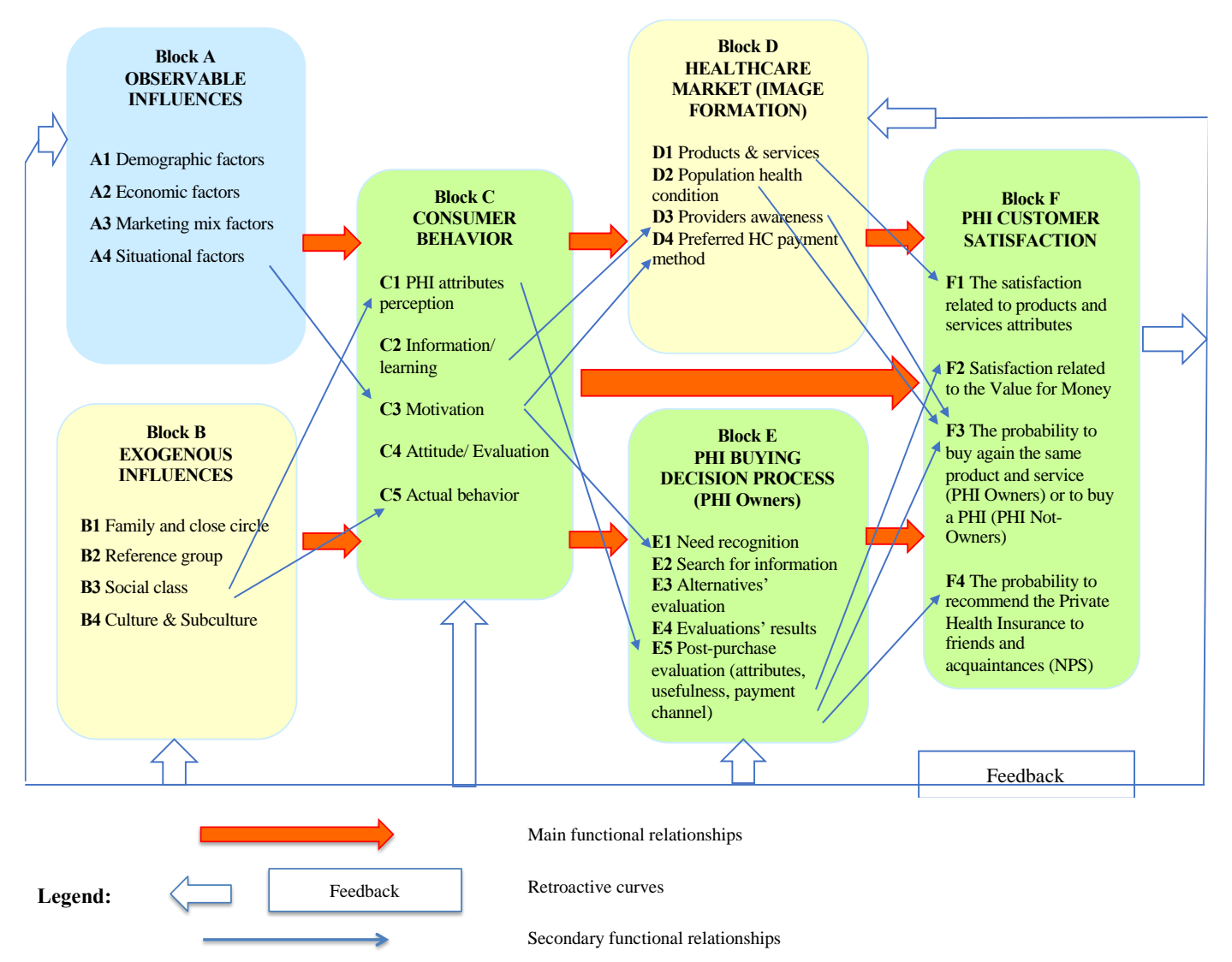

Figure 2. Starting conceptual model for customer satisfaction

Source: Author drawing, based on literature research.

Six independent variables sections were built in the proposed model and their functional relationships to dependent/ explained customer satisfaction variable, secondary functional relationships as well as backward curves (feedback) are included (Nicosia, 1966). Later, the two emerging paradigms toward customer satisfaction process - the firm's and consumer attributes loops - are developed in relation to psychological activities and post-purchase interactions (Tse et al., 1990).

\section{Model structure, variables, and their particularities}

The proposed model is structured on both morphological and functional layers to easily confirm the model conceptual valences. There are six constitutive blocks in the model morphology, with specific components subsumed in the overall system functionality, that is the research of the private health insurance consumer satisfaction and its drivers in all consumer buyer journey stages, from product attributes awareness to consideration to use them, buying decision and service usage. Three types of loops are used for accommodating system operation, the main loops, the secondary loops, and the feedback ones (Teodorescu et al., 2014).

\section{Morphology and functional relationships}

A systemic view was adopted to construct the model and as depicted in Figure 2, each of the six blocks include certain morphological components that are further described. 
Block A refers to direct observable influences such as demographic, economic, situational, and marketing mix specific factors. Based on Freudian model (Cătoiu \& Teodorescu, 2004) this section suggests consumer behavior motivational research from individual midst. Especially in the group Private Health Insurance, the demographic factor is very relevant in annual premium set up, the risk of illness and therefore claims being spread among the employee's demographic distribution. Another important aspect is the tax fiscal deductibility mentioned earlier, that provides a real fiscal advantage for the beneficiaries, both individual and company. This has been a competitive advantage of the Private Health Insurance (PHI) compared to HealthCare Subscriptions (HS) until 2017 when this advantage had been extended to these services as well (Romanian Governement, 2017). The medical event that required hospitalization was considered a situational factor, very important in determining if such events have further influence in PHI buying motivation.

Block $B$ - Exogeneous Influences - has in its structure the very important components for researchers to understand the cultural and regional influences as consumers have certain sets of traditions, customs and values they believe in, including the tangible ones such as the way they dress, where they live, what they invest in, and, in the same time, the discriminatory factors of social class. Following the more complex buyer behavior model created by John Howard in 1963, classified in marketing and social environment stimuli, from quality, price, distinctiveness, availability, and service of the brands to social influences such as family, reference groups and social class, the correlation between the PHI purchase, education and income level is an indicator of health care education and consideration in different population segments.

Block $C$ - The Consumer Behavior - proposes the measurement of the PHI attributes perception of owners and not owners for later validation and evaluation of both segments. When the perception of PHI attributes finds a situational context - such as hospitalization - the association between PHI and the healthcare service quality may become stronger or weaker, depending on the consumer medical experience compared to its expectations, which in case of owners, is related to the reason of purchase in the first place. In this context, it is possible to compare the perception of the 'complementary/ supplementary package' offered by private insurance providers on top of the public health insurance offered by the state for a potential privatepublic partnership.

Social influences, as exterior motivation introduced in Veblenian model (Cătoiu \& Teodorescu, 2004) for an individual, and the levels society affect consumer behaviors are strongly reflected in the actual healthcare behavior (C5)

Block $D$ - The Healthcare Market Image Formation - is designed based on marketing mix components, the 4 types of medical services offered in the market - the public health insurance, the occupational medicine, the PHI and the HCS, the population health condition related to the number of medical services accessed within 12 months across the country to understand the network coverage and the degree of its accessibility, the PHI providers awareness offered by both PHI owners and not-owner and the preferred HC payment method which brings to attention the informal payments issue, in case of emergencies or for expected better treatments.

Block $E$ depicts buying decision process stages. The complex decision-making process to purchase a Private health Insurance starts from the need recognition that is this case is very much based on the health condition and previous experiences such as hospitalization, associated with PHI attributes perception. The post-purchase evaluation considers the perceived service attributes as compared to the actual experience, the perceived service usefulness as compared to the actual product usage and is playing a significant role in customer satisfaction. Health related services are 
quite particular and customized to individuals, the post-purchase cognitive dissonance is based on the medical experience, then, even the user is satisfied once, it takes more positive medical events for the customer to repeat or recommend the product. The most important output variable is customer satisfaction that measures how the acquired products and services meet or surpass customer expectations after usage, which in Howard Sheth model is a feedback effect of purchasing, same as Attitude.

Block F - PHI Customer Satisfaction - has two components related to marketing mix, the customer satisfaction related to PHI attributes and related to its value for money and two components measuring the customer willingness to buy again the same product/service and to recommend it.

\section{General valences - processes and functionalities}

In the elaborated model scheme, there are highlighted three categories of functional relationships that are dependent on the model class and on the model morphology: main functional relationships which illustrate the fundamental connections between the blocks, secondary functional relationships depicted as structural connections between some components of different blocks, and retroactive curves to connect the consumer satisfaction in Block $F$ to all the other blocks. In the context of the model morphology, these functional relationships describe the process for the model to become operational.

The Observable Influences (Block A), through its 4 components, determines The Consumer Behavior (Block C). Within these relations, a distinct role is played by the situational factors (A4) such as the hospitalization required in the past 12 months, which activates the motivation factors (C3). Extrinsic motivation factor is the perceived usefulness of medical healthcare services while the intrinsic motivation factor is linked to the need of recognition (E1) in Buying Decision Process Block E, known (such as hospitalization in the past) or rather preventive, that is eventually the reason of a Private Health Insurance purchase.

The Exogeneous Influences (Block B) also determines the Consumer Behavior (Block C), this time the Social Class (B3) having a direct effect on Private Health Insurance perceived attributes $(\mathrm{C} 1)$ as well as on the consumer actual behavior (C5) related to medical healthcare products and services. Also, family, and close circle of friends (B1) is an important source and influences the information and learning (C2) since the PHI purchase decision is more driven by family and acquaintances recommendations.

Block C, contains all the elements related to the Consumer Behavior, from perception of PHI attributes, information and learning via promotional channels chosen by market players, motivation to buy or to use the healthcare services to attitude towards various services and actual behavior. It is obvious that the information provided by the market players will later contribute to their awareness (D3 in Healthcare Market Block) while the motivation will influence the preferred healthcare service payment method and channel, being related to the contextual events such as emergency hospitalization following an accident that requires immediate payment, whether formal or informal. In case of hospitalization, the motivation is linked with the need recognition in Block E (Buying Decision Process Block) and once activated, the expectation of the insurance owner is related to the reason of purchase and the initial predictions made in perception stage (C1) will influence the post-buy evaluation of products and services attributes, usefulness, payment channel and frequency (E5).

Block D (Healthcare market) determines Block $\mathrm{F}$ and has most influences on its components. There are specific and evident connections such as: 
D1 (the healthcare market products and services), associated with the competitive overview of the products and services attributes, influences the customer satisfaction related to them. To understand the overall PHI industry image, it is necessary to measure and make a comparison between the PHI owners and not-owners perception.

D2 (the population Health condition provided by HC usage frequency) and D3 (providers awareness) in determining the probability to buy again the same products and service in case of PHI owners, respectively to buy a PHI for not owners (F3).

D4 - the preferred HC payment method - that may be a reason and a strong motivation for some categories of people to rather prefer a PHI.

The Private Health Insurance Buying Decision Process (Block E) is the 3rd block that has a central role in the model, along with Block $\mathrm{C}$ and $\mathrm{D}$, within its functional relationships, being determined by Block $\mathrm{C}$ A specific role in this context is played by Post-purchase evaluation (E5) that determines not only the satisfaction related to the value for money - provided the premium payment preferences and price sensitivity analysis, but also the probability to buy again the same products or services (F3) and to recommend them to friends and acquaintances (F4).

\section{PHI Customer Satisfaction (Block F).}

For F1, that is determined by the general healthcare products and services (D1), the top two most used PHI providers were analyzed in terms of perceived PHI attributes importance and usefulness which eventually were considered the reason for customer satisfaction related to products and services attributes.

For F2, provided that the PHI premium is paid whether the covered medical services are used or not and regardless the claims, the satisfaction related to the value for money has materialized in the price sensitivity measurement.

Feedback curves generated by Block $\mathrm{F}$ to all the other blocks, determines a customer related reconsideration through possibly distinctive measurement levels for each block components. The probability to recommend PHI to friends an acquaintance from $\mathrm{F} 4$ could be later found in information and learning (C2) and consequently, in the promotional channels PHI providers choice.

Following the conceptual model described above and presented in Figure 2, a functional model based on structural equations has been drawn, as depicted in Figure 3.

\section{Methodology}

A quantitative study was conducted using a survey based on a questionnaire designed in accordance with the usual practices (Mardsen \& Wright, 2010) with questions developed to ensure both the clarity and the homogeneity of the scale points. The questions were adapted (Bearden et al., 1999; Bruner et al., 2001) and, to ensure uniformity of responses, all response options were limited to ten points after parceling. The measurement of values was done on a ten points scale, the same scale used in Romanian school grading system, where 1 stands for least and 10 for most. Each question in the questionnaire recorded distinct values for each variable represented in the theoretical cognitive model.

For sampling, a stratified sample method was used. Data collection was done by survey operators, both field and online in Bucharest and by telephone survey operators online in 9 counties and Bucharest, in large, medium, and small cities type. Data was collected as follows: Field data collection in Bucharest during June-August 2018 and during February - August 2019 to stratify gender/age results undertaken by that time. CATI, covering 4 regions and Bucharest during July August 2018. Online survey during September 2018 and March 2019. After data centralization, 
numerical and logical verification of the data, filtering of incomplete and erroneous answers, the data provided by 293 persons remained for analysis. Strictly, for the private health insurance proposed model, only 90 cases were retained, as the questionnaire enclosed supplementary questions to describe both private health insurance owners and non-owners.

Following the basic principle of sample reproducing the overall analyzed population structure, the selected sample for CATI was stratified, multistage and random for each individual in the target population to have the same chance to be captured in the study. The 4 stratification criteria, namely: 1) geographical region: Moldova, Muntenia, Transilvania and Bucharest; 2) city size (large $+100,000$ inhabitants, medium 50,000 - 100,000 inhabitants and small cities, under 50,000 inhabitants). Due to its particularities, Bucharest has not been classified as a large city and was treated separately; 3) gender (male, female); 4) age group (18-24, 25-34, 35-44, +45 years old), provided the sample representativeness for the studied target group and the interviewed individuals responses can be extrapolated to the entire target population in the calculated margin of error and at the established confidence level.

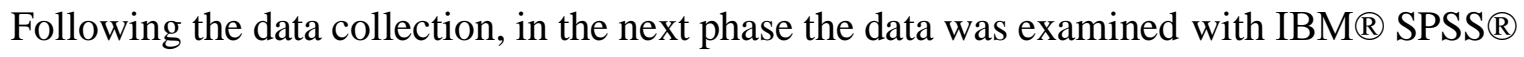
to check for deviations from normality. Skewness and kurtosis statistic were analyzed as well as the visual inspection of data (Kim, 2013). Skewness varies from -1.007 to 0.837 with a Std. Error of Skewness of 0.254. Kurtosis varies from -0.281 to 0.813 with a Std. Error of Kurtosis of 0.503. When a z-score is calculated (3.28), the value remains below the recommended 3.29 ratio for samples between 50 and 300 cases (Hoyle, 1995), and therefore could be concluded that the distribution of the sample is normal.

\section{Scale Validation}

In terms of latent dimensions, each model factor was measured by two composite indicators. Although the researchers' general recommendations are to describe each factor by three or four simple or aggregated indicators (Bollen, 1989; Hayduk \& Littvay, 2012), in this study, only two aggregated indicators could be considered, after repeated empirical trials. Every aggregated indicator was created by parceling two to fifteen simple indicators using arithmetic mean method.

The composite indicators attributed to each factor were tested for internal reliability (see Table 1) using Cronbach alpha coefficient (Cronbach, 1951). In the literature, values of at least 0.70 for the estimated confidence are considered acceptable (Nunnally, Bernstein \& Berge, 1967). The aggregate value of the Cronbach alpha coefficient associated with all 6 indicators used in the functional model, recorded the value of 0.78 , which indicates an acceptable overall internal reliability.

\section{Model specification and identification}

The collected and used data in the structural model supports the understanding of how much a private health insurance purchase is influenced by consumer behavior and by customer satisfaction. To interpret the valences of the theoretical proposed model it was used the structural equation modelling technique, using the maximum likelihood estimation technique in IBM ${ }^{\circledR}$ SPSS ${ }^{\circledR}$ AMOS $®$. As the structural equation model is partitioned fifty-fifty into the measurement model and the structural model, a Confirmatory Factor Model for estimation and a factor model for the underlying structural model were selected. The CFA model specifies the components, how the indicators are identified with each factor, and the connections among indicator errors. Then, the structural model depicts how the factors are interconnected (Brown, 2015). 
To get identified the model and specify it, the following assumptions and restrictions have been made. To address the errors associated with the accuracy of the combined indicator measurements, the variance error was left to freely vary for each indicator and, also the variance errors for all three latent factors were set to 1 (Kline, 2016). While holding these restrictions, the assumptions made have been tested and were explained on subsequently.

\section{Results and discussions}

\section{Model score validity test}

As the CFA model involves both measured and estimated values, score validity tests were performed. Convergent validity test results are presented in Table 1. All estimated standard loadings were higher than 0.5, suggesting good convergent validity (Fornell \& Larcker, 1981).

Table 1. Convergent validity test

\begin{tabular}{|c|c|c|c|}
\hline Construct & Items & Factor loadings $>\mathbf{0 . 5}$ & Cronbach alpha>0.7 \\
\hline \multirow{2}{*}{ PHI } & PHI 1 & 1.08 & 0.72 \\
\cline { 2 - 4 } & PHI 2 & 0.88 & 0.74 \\
\hline \multirow{2}{*}{ CS } & CS 1 & 0.63 & 0.75 \\
\cline { 2 - 4 } & CS 2 & 0.58 & 0.77 \\
\hline \multirow{2}{*}{ CB } & CB 1 & 0.68 & 0.76 \\
\cline { 2 - 4 } & CB 2 & 0.67 & 0.73 \\
\hline
\end{tabular}

Note: $\mathrm{PHI}=$ Private health insurance, $\mathrm{PHI} 1=$ Buying motivation attributes, $\mathrm{PHI} 2=$ Attitude towards premium payment options, $\mathrm{CB}=$ Consumer behavior, $\mathrm{CB} 1=$ Attitude towards promotion, $\mathrm{CB} 2=$ Perceived usefulness, $\mathrm{CS}=\mathrm{Customer}$ satisfaction, CS1 = Perceived and evaluated attributes and characteristics, CS2 = Importance of education per regions of development.

Source: Authors' own research.

Discriminant validity illustrates that the intercorrelations amongst factors assumed to measure different constructs are exceeding the inter-construct correlations (Tenenhaus \& Groupe, 2008) signifying acceptable discriminant validity (Table 2).

Table 2. Correlations and Square Root of the AVE

\begin{tabular}{|l|l|l|l|}
\hline & PHI & CB & CS \\
\hline PHI & $\mathbf{0 . 9 4 1}$ & & \\
\hline CB & 0.194 & $\mathbf{0 . 2 0 6}$ & \\
\hline CS & 0.127 & 0.028 & $\mathbf{0 . 1 3 5}$ \\
\hline
\end{tabular}

Note: $\mathrm{PHI}=$ Private health insurance, $\mathrm{CB}=$ Consumer behavior, $\mathrm{CS}=$ Customer satisfaction.

Source: Authors' own research.

\section{Model fit tests}

To validate the model's ability to correctly describe the values of the private health insurance analyzed, several fit indexes were compared. The use of multiple fit indexes is generally recommended by specialists (Tenenhaus \& Groupe, 2008), to ensure that the model's fit data. Values over 0.90 for indexes and values under 0.10 for errors wide-ranging indicate an acceptable rate of model fit. The proposed functional model proved acceptable fit to the data $(\chi 2 / \mathrm{DF}$ [1.228, $\mathrm{N}=90], \mathrm{GFI}=0.973, \mathrm{AGFI}=0.905 \mathrm{NFI}=0.977, \mathrm{CFI}=0.995, \mathrm{IFI}=0.996, \mathrm{TLI}=0.989, \mathrm{RMR}=0.022$, RMSEA=0.051). The standardized solution is shown in Figure 3. 


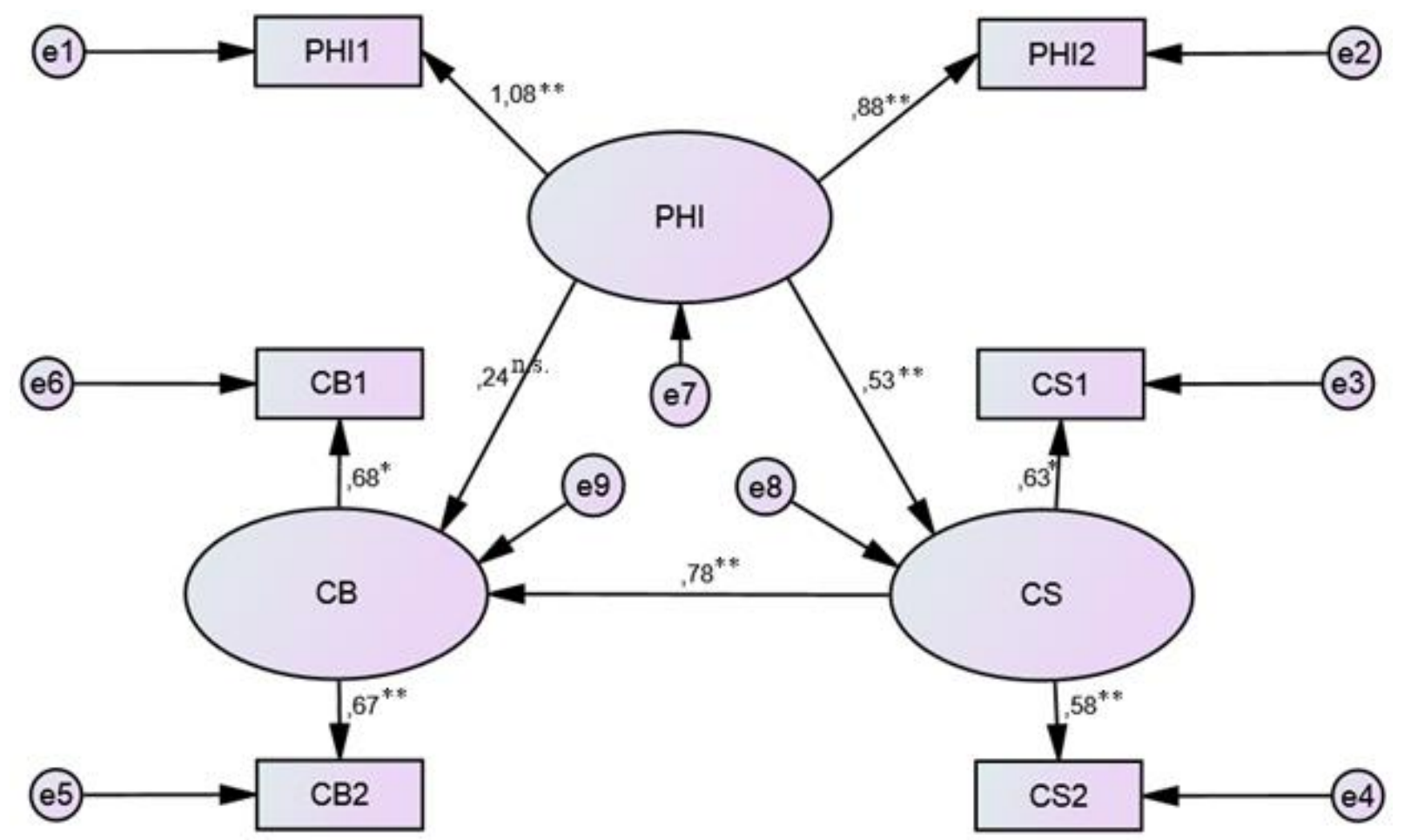

PICBE | 659

Figure 3. Proposed functional model with standardized parameter estimates

$* *=\mathrm{p}<0.001 ; *=\mathrm{p}<0.05 ;$ n.s. $="$ not significant"

Note: PHI $=$ Private health insurance, PHI1 = Buying motivation attributes, PHI2 = Attitude towards premium payment options, $\mathrm{CB}=$ Consumer behavior, $\mathrm{CB} 1=$ Attitude towards promotion, $\mathrm{CB} 2=$ Perceived usefulness, $\mathrm{CS}$ $=$ Customer satisfaction, CS1 $=$ Perceived and evaluated attributes and characteristics, CS2 = Importance of education per regions of development.

Source: Authors' own research.

\section{Model measurements}

Subsequently accepting the model giving the fit index values, the actual analysis of the accompanying hypotheses based on the statistical significance of the structural coefficients was carried out. The statistical results show that, only by its own characteristics and their price, a private health insurance direct influence on consumer behavior is rather weak (0.24). This result leads us to confirm and accept the first hypothesis, namely that The Private Health Insurance characteristics directly influence the consumer behavior in the buying process and based on the previous experience, subsequent repurchases.

Another way for the private health insurance to influence consumer behavior to a greater extend is tghrough customer satisfaction mediation. Therfore, the private health insurance beneficiaries develop a certain satisfaction or dissatisfaction degree level based on the product characteristics, the number of options included as well as the price paid for the covered services overall. For that reason, the second hypothesis The purchase of a Private health Insurance directly influences the consumer's level of satisfaction is also validated. In this case, the influence of the private health insurance on customer satisfaction is an average to strong extend (0.53). Building further on this idea, the private health insurance beneficiaries adapt their consumer behavior when renewing the insurance policy, according to their developed customer satisfaction level. 
Consequently, at every policy anniversary renewal moment, in time, the beneficiaries make a more educated choice for those product characteristics that best adapt on their specific situation, from both covered services and their price perspectives. The customer satisfaction interpose between private health insurance and consumer behavior influences the later relationship to a strong to very strong extend (0.78) and this validates the third hypothesis Customer Satisfaction mediates the Private Health Insurance purchase through consumer behavior. Based on the sample size, a bootstrapping mediation test was used to test the significance of the mediation. To reach a more precise result (Preacher \& Hayes, 2008), the number of bootstraps performed was set to 9000 samples and bias-corrected confidence intervals to $90 \%$ (Table 3). The direct effect of the Private Health Insurance purchase on Consumer Behavior is statistically non-significant which means the indirect effect of the Private Health Insurance purchase to Consumer Behavior is fully mediated through Customer Satisfaction.

Table 3. Bootstrapping mediation test

\begin{tabular}{|c|c|c|c|}
\hline Hypothesis & Direct effect & Indirect effect & Result \\
\hline $\begin{array}{l}\text { H3: Customer Satisfaction } \\
\text { fully mediates the Private } \\
\text { Health Insurance purchase to } \\
\text { Consumer Behavior. } \\
\text { PHI->CS->CB }\end{array}$ & $\begin{array}{l}\text { (PHI-> CB) } \\
0.243 \text { (n.s.) }\end{array}$ & $\begin{array}{c}(\mathrm{PHI}->\mathrm{CS}->\mathrm{CB}) \\
0.407^{* *}\end{array}$ & Full mediation \\
\hline
\end{tabular}

$* *=\mathrm{p}<0.001 ;$ n.s. $="$ not significant"

Note: $\mathrm{PHI}=$ Private health insurance, $\mathrm{CB}=$ Consumer behavior, $\mathrm{CS}=$ Customer satisfaction.

Source: Authors' own research.

The PHI depends to a very large extend on the covered package policy, translated into product attributes, as shown when analysing how each factor of the model is described by the indicators that measure it. The PHI 1 aggregate indicator was calculated by parceling fifteen simple indicators, however, the intercorrelations or inter-associations among the primary variables prompted a state of multicollinearity among items. There are very good values of fit indexes that proves the multicollinearity has not affected to a very large extend the entire experimental model, nevertheless the specialists (Rocha \& Chelladurai, 2012; Roche \& al. 2019) note that in some situations, the parceling aggregate indicators associated values may exceed normal variation limits. The PHI 1 is the only indicator with limits exceeding this way recording the value of 1.08 . When comparing PH 1 to PHI 2 which is another aggregate indicator made of primary indicators that defined the payment options, it can be stated that the PHI overall is influenced by features and attributes in the first place followed closely by payment options.

The Consumer Behavior factor is measured by the exposure to promotional messages boradcasted by private health insuracne providing companies and by perceived usefulness of a private health insurance in somewhat equal proportions. The Customer Satisfaction factor depends to a slightly greater extend on product perceieved characteristics and attributes, followed with a close value by the education importance per regions of developement.

\section{Conclusions}

The private health insurance market in Romania is a complex market, driven by legislative measures, by unknown and unpredictable variables that can occur at any time, as proven by each of the sanitary crises that appeared at some point. This study, which started from an initial cognitive 
model and has been complemented by the experimental functional model, presents the private health industry radiography for Romania in the years 2017-2019.

During the COVID -19 pandemic, several studies have shown the interest of population in a private health insurance however, these situations should rather be in a complementary/ supplementary package on top of the basic public health package coverage whose capacity to cover these specific needs is limited. At the same time, further studies need to be elaborated regarding the private medical services capacity to cover this type of urgencies and therefore, to justify the premium price paid, on top of the social health insurance contribution, should this be paid by employer, as an extra salary benefit, or by the individual itself, as proven track record by other European countries.

The modeling instrument proves to be useful in scientific studying the customer satisfaction of such volatile market, being based on pragmatic systemic approach along customer journey, from the past experiences related to medical services, to reasons to repurchase a private health insurance. Based on the model described relationships, a private health insurance provider will improve its services, will adapt the products to increase the individuals' motivation to purchase a private health insurance policy and will take the needed steps for the after sale increased customer satisfaction.

This study has also some limitations. Even if the structural equation modeling shows relevant results on reduced samples, the future studies, larger samples based, may lead to the more complex functional models constructs that are using non aggregated and thus, non-parceled primary indicators. Another limitation of the study is related to the data collection period, namely before the pandemic start. Resuming the study now, after one year of health-related constraints, pandemic triggered, could highlight more sensitive aspects of consumer preferences changes.

\section{References}

Bearden, W. O., William, B., Bearden, W. A., Netemeyer, R. G. (1999). Handbook of marketing scales: Multi-item measures for marketing and consumer behavior research, Sage.

BNR (2019). Curs Valutar Mediu (lunar și anual) https://www.cursbnr.ro/curs-valutar-mediu.

Boone, J. (2018). Basic versus supplementary health insurance: access to care and the role of cost effectiveness, Journal of health economics, 60, 53-74.

Bollen, K. (1989). Structural equations with latent variables. Wiley Series in probability and mathematical statistics. Applied probability and statistics section.

Brown, T. A. (2015). Confirmatory factor analysis for applied research. Guilford publications.

Bruner, G.C., Hensel, P.J., \& James, K. E. (2001). Marketing Scales Handbook, Chicago, American Marketing Association.

Capatina, E. (2020). Selection in employer sponsored health insurance, Journal of health economics, 71, https://doi.org/10.1016/j.jhealeco.2020.102305.

Cătoiu, I., \& Teodorescu, N. (2004). Comportamentul Consumatorului (2nd ed.). Uranus.

Cheng, S. H., Chen, C. C., \& Chang, W. L. (2009). Hospital response to a global budget program under universal health insurance in Taiwan, Health Policy, 92(2-3), 158-164.

Cronbach, L. J. (1951). Coefficient alpha and the internal structure of tests, Psychometrika, 16, 297-334.

Dang, A., Dang, D., \& Vallish, B. N. (2021). Importance of Evidence-Based Health Insurance Reimbursement and Health Technology Assessment for achieving Universal Health Coverage and Improved Access to Health in India, Value in Health Regional Issues, 24, 24-30. 
Fornell, C., Larcker, D.F. (1981). Structural equation models with unobservable variables and measurement errors, Algebra and statistics, J. Mark. Res., 18 (1), 39-50.

Hayduk, L. A., Littvay, L. (2012). Should researchers use single indicators, best indicators, or multiple indicators in structural equation models?, BMC Med. Res. Method. 12(1), 159.

He, A.J., Qian, J., Chan, W.S., \& Chou, K.L. (2020). Preferences for private long-term care insurance products in a super-ageing society: A discrete choice experiment in Hong Kong, Social Science \& Medicine, https://doi.org/10.1016/j.socscimed.2020.113632.

PICBE |

Heim, B., Lurie, I., Mullen, K. J., \& Simon, K. (2021). How Much Do Outside Options Matter? The Effect of Subsidized Health Insurance on Social Security Disability Insurance Benefit Receipt, Journal of Health Economics, 102437.

Hoyle, R.H. (1995). Structural equation modeling: Concepts, issues, and applications, Sage.

INSSE (2019a). Castigul salarial nominal mediu brut lunar, pe categorii de salariati, forme de proprietate, activitati (sectiuni si diviziuni) ale economiei nationale CAEN Rev. 2 si pe sexe http://statistici.insse.ro:8077/tempo-online/\#/pages/tables/insse-table, FOM107F.

INSSE. (2019b). Numarul mediu al salariatilor pe categorii de salariati, forme de proprietate, macroregiuni, regiuni de dezvoltare si judete http://statistici.insse.ro:8077/tempoonline/\#/pages/tables/insse-table, FOM104B.

Kim, H.Y. (2013). Statistical notes for clinical researchers: assessing normal distribution using skewness and kurtosis, Restor Dent Endod., 38(1), 52-54.

Kline, R.B. (2016). Principles and practice of structural equation modeling. Fourth Edition, The Guilford Press.

Kullberg, L., Blomqvist, P., \& Winblad, U. (2019). Health insurance for the healthy? Voluntary health insurance in Sweden. Health Policy, 123(8), 737-746, https://doi.org/10.1016/ j.healthpol.2019.06.004.

Lim, K.M. (2020). Public provision of health insurance and aggregate saving in an overlapping generations model with endogenous health risk: The South Korean case, Economic Modelling, 91, 233-246.

Marsden, P.V., \& Wright, J.D. (Eds.) (2010). Handbook of survey research, Emerald Group Publishing, ISBN: 978-1-84855-224-1.

Malhotra, N. K., Nunan, D., \& Birks, D.F. (2017). MARKETING Research - an applied approach (Fifth). Pearson Education Limited.

Matsunaga, M. (2008). Item Parceling in Structural Equation Modeling: A Primer. In Communication Methods and Measures, 2(4), https://doi.org/10.1080/19312450802458 935.

Nicosia, F.M. (1966). Consumer Decision Processes. Marketing and Advertising implications (1966th ed.). Prentice-Hall.

Nunnally, J. C., Bernstein, I.H., Berge, J.M.T. (1967). Psychometric theory, McGraw-Hill, New York.

Preacher, K.J., \& Hayes, A. F. (2008). Contemporary approaches to assessing mediation in communication research. In A.F. Hayes, M.D. Slater, \& L.B. Snyder (Eds.), The Sage sourcebook of advanced data analysis methods for communication research, 13-54, Thousand Oaks, CA: Sage.

Puri, R., \& Sun, C. (2020). Increasing utilization of public health insurance programs: Evidence from an experiment in India. World Development, 139, https://doi.org/10.1016/j.worlddev. 2020.105321. 
Rocha, C. M., \& Chelladurai, P. (2012). Item parcels in structural equation modelling: An applied study in sport management, International Journal of Psychology and Behavioral Sciences, 2(1), 46-53.

Roche, K.M., Little, T.D., Ghazarian, S.R., Lambert, S.F., Calzada, E.J., \& Schulenberg, J.E. (2019). Parenting processes and adolescent adjustment in immigrant Latino families: The use of residual centering to address the multicollinearity problem, Journal of Latinx Psychology, 7(1), 6.

PICBE |

663

Romanian Governement (2017). Emergency Ordinance no 3/2017. Official Monitor, 3, 2, point 8. Sheth, J. N., \& Howard, J.A. (1969). The theory of buyer behavior. New York: Wiley.

Ștefan, A. (2020). Câți români au o asigurare privată de sănătate. Ro Health Review Strategies, Economics \& More, https://rohealthreview.ro/cati-romani-au-o-asigurare-privata-de-sana tate/.

Teodorescu, N., Pârgaru, I., Stancioiu, A. F., Matei, E., \& Botoş, A. (2014). Modelling the image research of a tourism destination. Amfiteatru Economic Journal, 16 (Special No. 8), 1076-1088.

Tenenhaus, M., Groupe, H. (2008). Structural Equation Modelling for small samples, Groupe HEC.

Trinh, C. T., Nguyen, X., Sgro, P., \& Pham, C. S. (2020). Culture, financial crisis and the demand for property, accident and health insurance in the OECD countries, Economic Modelling, 93, 480-498.

Tse, D. K., Nicosia, F. M., \& Wilton, P. C. (1990). Consumer Satisfaction as a Process. Psychology \& Marketing, 7(3), 177-193, https://doi.org/10.1002/mar.4220070304.

Zilberberg, M.D., Tjia, J, Shorr, A.F. (2020). Bang for Your Buck: Could Medicare's Hospital Value-Based Purchasing Program Rein in Health-Care Spending in Pneumonia. Population and Quantitative Health Sciences Publications, https://doi.org/10.1016/j.chest.2019.12. 026. Retrieved from https://escholarship.umassmed.edu/qhs_pp/1352.

DOI: 10.2478/picbe-2021-0061, pp. 650-663, ISSN 2558-9652 |

Proceedings of the $15^{\text {th }}$ International Conference on Business Excellence 2021 